\title{
Expression of P53, PTEN and S100A4 in invasive ductal breast cancer and the clinical significance
}

\author{
Zhang gang ${ }^{1}$, Li zhong ${ }^{1}$, Lin Xiao-meng ${ }^{1}$, Zhang Jun-hua ${ }^{1}$, Cui Yong', Zhao xing ${ }^{2}$ \\ ${ }^{1}$ Hospital of Hebei University, China, ${ }^{2}$ Hospital of Chengde Medical College
}

\section{A B S T R A C T}

Objective: To investigate the expression level of P53, PTEN and S100A4 in invasive ductal breast cancer and the clinical significance. Methods: SP immunohistochemical and Western blot analysis were used to detect the expression of P53, PTEN and S100A4 protein in invasive ductal breast cancer, adjacent tissues and benign breast lesions. The results were aimed to explore the correlation of p53, PTEN, S100A4 and analyze the relationship between indicators and clinical pathology. Results: Immunohistochemical results showed that the positive rates of p53 and S100A4 in invasive ductal breast cancer were $47.69 \%$ and $56.92 \%$, which were significantly higher than that in benign breast lesions $(16.00 \%, 22.00 \%)(p<0.05)$; The positive rates of PTEN in invasive ductal breast cancer was $24.62 \%$, which were significantly lower than that in benign breast lesions $(52.00 \%)$ $(p<0.05)$; The expression of p53 was negatively correlated with PTEN in invasive ductal breast cancer $(p<0.05)$. Western blot results revealed that the relative expression levels of p53, PTEN and S100A4 protein in invasive ductal breast cancer were $0.967 \pm 0.066$, $0.785 \pm 0.044,1.065 \pm 0.073$, which were significant difference with that in benign breast lesions $(0.549 \pm 0.032,1.245 \pm 0.059,0.370 \pm 0.065)(p<0.05)$; The expression of $p 53$ has correlation with histological differentiating degree and lymph node metastasis $(p<0.05)$, but it was irrelevant to the age, tumor size and clinical grade $(p>0.05)$. The expression of S100A4 has correlation with clinical grade and lymph node metastasis $(p<0.05)$, but no association with the age, tumor size and histological differentiating degree was observed in this study $(p>0.05)$. The expressions of PTEN has correlation with lymph node metastasis $p<0.05$, but no association with the age, tumor size, clinical grade and histological differentiating degree was noted in our study ( $p>0.05)$. Conclusion: Expression of P53, PTEN and S100A4 can be expected to be taken as to the prognosis biomarkers of breast cancer and potential targets for new and effective treatment strategies for breast cancer.

Key words: Invasive ductal breast cancer; P53; PTEN S100A4; Immunohistochemistry; Western blot

\section{INTRODUCTION}

Breast cancer, as we all known, is one of the most common malignancy. In China, the morbidity of breast cancer has rising up since 1970s. What's worse, a tendency towards increased incidence in younger women has been found in a large of studies and more aggressive clinical behavior in the younger patients was also noted. Breast cancer has become a big public health problem in our society, however, the exact mechanism of breast cancer remains unknown. P53, a common tumor suppressor, is located 17P131 and the expression level is low under normal circumstance, but the expression quantity will increase if stimulated by some pathological factors including chemical substances, lacking of oxygen, ultraviolet rays and so on. S100A4 belongs to protein S-100 family which can combined with calcium ion easily. In physiological condition, S100A4 involved in the interaction of cytoskeleton, cellular membrane, calcium signaling and cell differentiation. At the same time, S100A4 can promote angiogenesis, which closely connected with a series of processes of tumorigenesis, development and transfer. PTEN is a member of the family of protein tyrosine phosphatases and its loss of expression was found in a wide variety of tumors, but the relationship between 
PTEN and breast cancer has yet to be further studied. Immunohistochemistry and Western blot were employed to investigate P53, PTEN and S100A4 expression level of breast cancer and benign lesions of the breast tissue in this study. The results were explored the correlation between the three biomarkers, and analyzed invasive ductal breast cancer and the clinical significance

\section{MATERIALS AND METHODS}

\section{Materials}

One hundred and thirty female patients diagnosed with breast invasive carcinoma at the affiliated hospital of Hebei University between June 2008 and June 2012 was included in this study. Fifty samples were selected of corresponding tissue adjacent to carcinoma edge measuring $\geq 5 \mathrm{~cm}$ as adjacent noncancerous tissue and 50 samples of hyperplasia of mammary glands and fibroadenoma of breast as benign lesion. All of the primary patients, without chemotherapy, radiotherapy or hormone therapy before surgical resection, were recorded the gender, age, tumor size, clinical stage, the largest microscopy tumor histologic type, histologic grade and lymph node metastasis. A manual immunohistochemical procedure was performed using $4 \mu \mathrm{m}$ thick tissue sections. Then HE staining and immunohistochemical. Thirty cases of breast infiltrating ductal carcinoma and benign lesions with fresh tissue were carried out for experiment. Western blot was applied to detect the expression level of Clusterin, PTEN and S100A4.

Reagent: Rabbit anti P53, PTEN and S100A4 monoclonal antibody used in this study were bought from Chinese fir jinqiao biological technology co., LTD., Beijing.SP kit and $\mathrm{DAB}$ chromogenic agent which were bought from Fujian new technology co., LTD.

Immunohistochemical (IHC) Specific SP immuno histochemical steps were according to the kit instructions Positive control groups were provided by reagent company and PBS was regarded as negative control groups. Results: P53 positive products were mainly in the nucleus, PTEN and S100A4 positive products were mainly in the cytoplasm. Either nuclear or cytoplasmic appeared claybank or dark brown was considered to be positive labeling. Positive cells of the tumor cells for $0-5 \%$ scored as $0,6-20 \%$ as $1,21-50 \%$ as $2, \geq 50 \%$ as 3 . The expression intensity of 0 and 1 was classified as negative, 2 and 3 as positive.

Western blot Fresh with lesion tissues were kept in $-80^{\circ} \mathrm{C}$ temperature and total protein were extracted, total protein concentration was determined by BCA protein concentration. Thirty microgram of protein samples were transferred to the polyvinylidene fluoride membrane on 10\% SDS-PAGE electrophoresis. After TBST liquid containing 5\% skimmed milk closed, each membrane respectively incubated with anti-1. PVDF membrane washing three times then ECL color and exposed in dark room. Read the stripes width and grey value by Image J Image. The data was analyzed by Statistical Microsoft.

Analysis with statistics SPSS18.0 statistical was used to analyze data. Chi-square test examined the relationship between protein expression and clinical pathological indicators ( $p<0.05$ as statistically significant) Western blot results were expressed with $\bar{x} \pm \mathrm{S}$, with independent sample t test (Independent sample t text), according $\mathrm{p}<0.5$ to outstanding difference.

\section{RESULTS}

The expression of P53, PTEN and S100A4 in ductal breast cancer, adjacent tissues and benign breast lesions

P53 expression was defined as predominantly in cell nucleus, but PTEN and S100A4 were assembled in the cytoplasm. The expression lever of P53 and S100A4 in ductal breast cancer were higher than in benign breast lesion, but the expression of PTEN in ductal breast cancer was lower than in benign cancer lesion. The results are listed in Table 1.

The expression of P53, PTEN and S100A4 in ductal breast cancer and benign breast lesion were tested by Western blot

Figure 1 shows us the results. The expression quantity of P53, PTEN and S100A4 in ductal breast cancer are $0.967 \pm 0.066,0.785 \pm 0.044,1.065 \pm 0.073$, which is significance compared to benign breast lesion $(0.549 \pm 0.032$, $1.245 \pm 0.059,0.370 \pm 0.065)(\mathrm{P}<0.05)$.

The correlation of the expression of P53, PTEN and S100A4 and clinical pathological parameters

In invasive ductal carcinoma, the expression of P53 in lymph node metastasis, poorly differentiated group was higher, and the difference between group with statistically significance $(\mathrm{P}<0.05)$. S100A4 is associated with lymph node metastasis and clinical stage, with significant difference between groups $(\mathrm{P}<0.05)$. The expression of PTEN is related to lymph node metastasis $(\mathrm{P}<0.05)$. The details are mentioned in Table 2.

The correlation among the expression of protein P53, PTEN and S100A4 in breast cancer

Among 130 breast cancer patients, the expression of P53 and PTEN has negative correlation $(\mathrm{r}=-0.188, \mathrm{P}<0.05)$, the expression of P53 and S100A4 has no correlation 


\begin{tabular}{|c|c|c|c|c|c|c|c|c|c|c|}
\hline \multirow[t]{2}{*}{ Project } & \multirow[t]{2}{*}{ Numbers } & \multicolumn{2}{|c|}{ P53 } & \multirow[t]{2}{*}{$\mathbf{P}$} & \multicolumn{2}{|c|}{ S100A4 } & \multirow[t]{2}{*}{$\mathbf{P}$} & \multicolumn{2}{|c|}{ PTEN } & \multirow[t]{2}{*}{$\mathbf{P}$} \\
\hline & & $\begin{array}{l}\text { Positive } \\
\text { numbers }\end{array}$ & $\begin{array}{c}\text { Positive } \\
\text { rates }\end{array}$ & & $\begin{array}{l}\text { Positive } \\
\text { numbers }\end{array}$ & $\begin{array}{c}\text { Positive } \\
\text { rates }\end{array}$ & & $\begin{array}{l}\text { Positive } \\
\text { numbers }\end{array}$ & $\begin{array}{c}\text { Positive } \\
\text { rates }\end{array}$ & \\
\hline Benign breast lesion & 50 & 8 & 16 & $0.09 \star$ & 11 & 22 & $0.00 \star$ & 26 & 52 & $0.22 \star$ \\
\hline Adjacent tissue & 50 & 17 & 34 & $0.00 \bullet$ & 12 & 24 & $0.00 \bullet$ & 21 & 42 & $0.00 \bullet$ \\
\hline Ductal breast cancer & 130 & 62 & 47.69 & $0.03 \boldsymbol{\Delta}$ & 74 & 56.92 & $0.81 \Delta$ & 32 & 24.62 & $0.31 \wedge$ \\
\hline
\end{tabular}

$\star$ The comparison between adjacent tissue and ductal breast cancer, $\bullet$ The comparison between ductal breast cancer and benign breast lesion, $\mathbf{\Delta}$ The comparison between adjacent tissue and benign breast lesion

\begin{tabular}{|c|c|c|c|c|c|c|c|c|c|c|}
\hline \multirow[t]{2}{*}{ Clinical factors } & \multirow[t]{2}{*}{$\mathbf{n}$} & & & \multirow[t]{2}{*}{$\mathbf{P}$} & & & \multirow[t]{2}{*}{$\mathbf{P}$} & & & \multirow[t]{2}{*}{$\mathbf{P}$} \\
\hline & & \multicolumn{2}{|c|}{ Positive rate (\%) } & & \multicolumn{2}{|c|}{ Positive rate (\%) } & & \multicolumn{2}{|c|}{ Positive rate (\%) } & \\
\hline \multicolumn{11}{|l|}{ Age (years) } \\
\hline$\leq 50$ & 52 & 21 & 40.38 & 0.173 & 26 & 50.00 & 0.193 & 11 & 21.15 & 0.454 \\
\hline$>50$ & 78 & 41 & 52.56 & & 48 & 61.54 & & 21 & 26.92 & \\
\hline \multicolumn{11}{|l|}{ Cancer length } \\
\hline$\leq 2$ & 46 & 19 & 41.3 & 0.281 & 25 & 54.34 & 0.661 & 13 & 28.26 & 0.475 \\
\hline$>2$ & 84 & 43 & 51.19 & & 49 & 58.33 & & 19 & 22.62 & \\
\hline \multicolumn{11}{|c|}{ Histology classification } \\
\hline$|-| \mid$ & 113 & 50 & 44.25 & 0.043 & 64 & 56.64 & 0.865 & 30 & 26.55 & 0.187 \\
\hline III & 17 & 12 & 70.59 & & 10 & 58.82 & & 2 & 11.76 & \\
\hline \multicolumn{11}{|l|}{ Clinical stages } \\
\hline$I-I I$ & 82 & 38 & 46.34 & 0.687 & 40 & 48.78 & 0.014 & 30 & 26.55 & 0.444 \\
\hline III & 48 & 24 & 50.00 & & 34 & 70.83 & & 2 & 11.76 & \\
\hline \multicolumn{11}{|c|}{ Lymph node metastasis } \\
\hline Yes & 58 & 35 & 60.34 & 0.010 & 42 & 72.41 & 0.001 & 9 & 15.51 & 0.040 \\
\hline No & 72 & 27 & 37.50 & & 32 & 44.44 & & 23 & 31.94 & \\
\hline
\end{tabular}

\begin{tabular}{llllll}
\multicolumn{3}{l}{ Table 3: The correlation among the expression of } \\
protein P53、 PTEN and S100A4 in breast cancer
\end{tabular}

$(\mathrm{r}=0.084, \mathrm{P}>0.05$, the expression of PTEN and S100A4 has no correlation $(\mathrm{r}=-0.044, \mathrm{P}>0.05)$.

\section{DISCUSSION}

P53 located in chromosome $17 \mathrm{p} 131,{ }^{1}$ highly conserved DNA sequence consisted by 393 amino acid composition and molecular weight of 53000 proteins. Wild-type P53, a tumor suppressor, can negatively regulate cell growth, monitor the integrity of the cell genome, repair DNA damage and remove all kinds of harmful cells. Once gene mutation, occurred in P53 will cause cell malignant transformation and loss normal physiological role. ${ }^{2}$ Wildtype p53 is easy to degrade because of the short half-life, but the mutant p53 can gather the tumor cell nucleus and

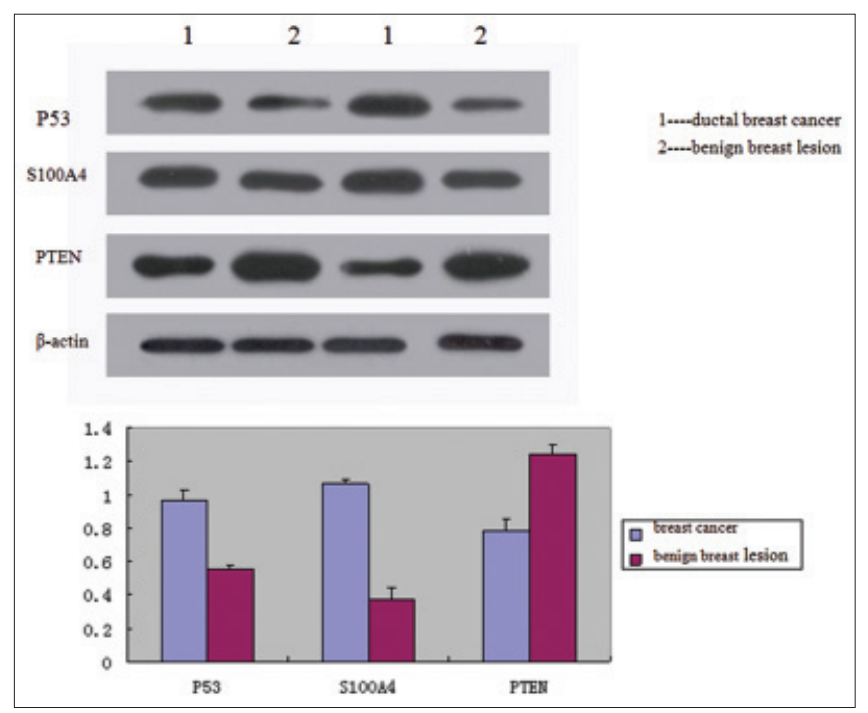

Figure 1: The expression of P53, PTEN and S100A4 in ductal breast cancer and benign breast lesion by Western-blot method

promote the occurrence of tumor. So mutant p53 were detected as specific abnormal gene expression in many organizations by using immunohistochemical method in this study. Many studies have reported that p53 and cell cycle proteins (cyclins) can combine complex formation, which causes the cell stagnation in the G1 phase or 
programmed cell death through restraining cell cycle related protein kinases (CDKs). ${ }^{3}$ This study showed that the positive expression rate of p53 in 130 cases of breast cancer tissues was $47.69 \%$ (62/130). However, 50 cases of breast cancer tissues was $34 \%(17 / 50)$ and 50 cases of breast benign lesions tissues was $16 \%(8 / 50)$, the difference is statistically significant. The expression level of p53 was high in both lymph node metastasis groups and poor differentiated groups, and the difference between groups has statistically significance $(\mathrm{P}<0.05)$. It is consent with Ye $\mathrm{X}^{4}$ and $\mathrm{Li} \mathrm{ZD}^{5}$, etc.

S100A4 is closely related to tumor metastasis. ${ }^{6} \mathrm{It}$ is molecular weight of $11.5 \mathrm{kd}$ composed of 101 amino acids located in $1 \mathrm{q} 21$. Under normal physiological condition, S100A4 is involved in different physiologic processes, including interaction of cytoskeleton, cellular membrane, calcium signaling and cell differentiation. It can promote the formation of blood vessels and increase the ability of the tumor in the process of tumor growth. Hua $\mathrm{J}^{7}$ concluded that expression level of S100A4 protein in gastric was higher than in normal tissue cancer tissues. Maelandsmo ${ }^{8}$ proved that the expression of S100A4 existed in the cytoplasm and nucleus of all kinds cancer tissues, including the ovarian primary tumors, metastases. Rud 1 and $\mathrm{PS}^{9}$ proved that expression of S100A4 in breast cancer had nothing to do with age and tumor histologic grade, but was closely related with lymph node metastasis. This study results showed that the expression of S100A4 protein in breast cancer was higher than the adjacent tissues and benign lesions and associated with lymph node metastasis and clinical stage, which is similar with others. It has significant difference in statistics $(\mathrm{P}<0.05)$.

PTEN is located in $10 \mathrm{q} 23$ and belongs to the protein phosphate kinase family. The lacks of PTEN protein were found in the most of malignant tumor or mutations. Zhang $Z^{10}$ showed that loss of PTEN expression in esophageal cancer tissues, which negatively correlated with lymph node metastasis by detecting the expression of PTEN in 60 cases of esophageal cancer tissues and 40 cases of normal esophageal mucosa tissues. He speculated that PTEN methylation may be lead to cell proliferation and formation of tumors through low levels of transcription. Some researches reported the lack expression of PTEN in endometrial carcinoma, ${ }^{11}$ which may be related to reducing the inhibition of AKT pathway. The results in this study shows that the expression of PTEN in ductal breast cancer is notable lower than in benign breast lesion, which is accordance with above results.

By examining the expression of P53 and PTEN in 130 ductal breast cancer, we concluded that the expression of P53 was negatively correlated with PTEN ( $r=-0.188$, $\mathrm{P}<0.05)$. Stambolic ${ }^{12}$ believed the P53 may induce PTEN transactivation by combining with P53 elementation of PTEN upstream gene and in by using of missing and mutation analysis. Studies have shown that one of the reasons for the decrease expression of PTEN may be caused by p53 mutation in pancreatic cancer drops, Mayo et $a l,{ }^{13}$ showed that transfection of wild-type p53 can promote the high expression of PTEN. It was probably associated with activation of PTEN promoter, then it may reduce the expression of PTEN. P53 can physically combine with S100A4. ${ }^{14}$ It can regulate the proliferation of tumor cells by adjusting S100A4 mutant P53 activity and the interaction with $\mathrm{p} 53$. Thus, the high expression level of S100A4 and p53 and the loss of PTEN may be involved in breast cancer. Nevertheless, our results may serve as a potential therapeutic target for diagnosis and treatment of breast cancer.

\section{REFERENCES}

1. Marc L, Robert- Alain T and Guy L. p53 and breast cancer, an update Endocrine- Related Cancer 2006; 13(2): 293.

2. Halasova E, Adamkov M, Matakova T, Vybohova D, Antosova M, Janickova M, et al. Expression of Ki-67, Bcl-2, Survivin and p53 Proteins in Patients with Pulmonary Carcinoma. Adv Exp Med Biol 2013;756:15-21.

3. Nowakowski A, de Souza SC, Jach R, Rosillon D, Książek A and Holl K. HPV-Type Distribution and Reproducibility of Histological Diagnosis in Cervical Neoplasia in Poland. Pathol Oncol Res 2014.

4. Ye X, Zhang C, Chen $\mathrm{Y}$, and Zhou T. Upregulation of Acetylcholinesterase Mediated by p53 Contributes to CisplatinInduced Apoptosis in Human Breast Cancer Cell. J Cancer 2015; 6(1):48-53.

5. Li ZD, Wang K, Yang XW, Zhuang ZG, Wang JJ and Tong XW. Expression of aryl hydrocarbon receptor in relation to $\mathrm{p} 53$ status and clinicopathological parameters in breast cancer. Int J Clin Exp Pathol 2014; 7(11):7931-7937.

6. Wang Y, Zhou LB and Li XH. S100A4 expression and prognosis of gastric cancer: a meta-analysis. Genet Mol Res 2014; 13(4):10398-10403.

7. Hua J, Chen D, Fu H, Zhang R, Shen W, Liu S, et al. Short hairpin RNA-mediated inhibition of S100A4 promotes apoptosis and suppresses proliferation o BGC823 gastric cancer cells in vitro and in vivo. Cancer Lett 2010; 292(1): 41-47.

8. Maelandsmo GM, Flørenes VA, Nguyen MT, Flatmark K and Davidson B. Different expression and clinical role of S100A4 in serous ovarian carcinoma at different anatomic sites. Tumor Biol 2009; 30(1):15-25.

9. Rudland PS, Platt-Higgins A, Renshaw C, West CR, Winstanley $\mathrm{JH}$, Robertson L, et al. Prognostic Significance of the metastasis inducing protein S100A4 (p9Ka) in hum an breast cancer. Cancer Res 2000; 60 (6): 1595-1603.

10. Zhang Z, Xiao H, Xie F, Zhang H, Chen C, Xiao H, et al. Highincidence of PTEN mutations in Chinese patients with primary small cell carcinoma of the esophagus. BMC Cancer 2014; 14:19.

11. Han SY, Kato $H$, Kato $S$, Suzuki T, Shibata $H$, Ishii $S$, et al. Functional evaluation of PTEN missense mutations using in vitro 
phosphoinositide phosphatase assay. Cancer Res 2006; 60(12): 3147-3151.

12. Stamblic V, Macphelon D, Sas D, etal. Seguhaon of transcription by p53 [J]. Mol Gel. 200I, 8:317. 325.

13. Mayo LD, Dixon JE, Durden DL, Tonks NK and Donner DB.
PTEN protects $\mathrm{p} 53$ from $\mathrm{Mdm}$ and sensitizes cancer cells to chemotherapy. J Biol Chem 2002; 277(7): 5484-5489.

14. Orre LM, Panizza E, Kaminskyy VO, Vernet E, Gräslund T, Zhivotovsky B, et al. S100A4 interacts with p53 in the nucleus and promotes p53 degradation. Oncogene 2013; 32(49):5531-5540. 